\title{
Prediction of scaled feed intake in weaner pigs using physico-chemical properties of fibrous feeds
}

\author{
S. P. Ndou, R. M. Gous and M. Chimonyo* \\ Animal and Poultry Science, University of KwaZulu-Natal, P. Bag X01 Scottsville 3209, Pietermaritzburg, South Africa
}

(Submitted 18 May 2012 - Final revision received 16 November 2012 - Accepted 17 November 2012 - First published online 23 January 2013)

\begin{abstract}
The objective of the present study was to predict scaled feed intake (SFI) using the physico-chemical measurements of feed bulk, such that gut capacity can be estimated in weaner pigs. A basal feed with $13.7 \mathrm{MJ}$ digestible energy and $180 \mathrm{~g}$ crude protein per kg DM was diluted to six inclusion levels $(0,80,160,240,320$ and $400 \mathrm{~g} / \mathrm{kg} \mathrm{DM})$ using lucerne hay, maize cob, maize stover, sawdust, sunflower husks or grass hay (veld grass). A total of 124 pigs weighing $18 \cdot 1$ (SD 1.37) kg body weight were used. Water-holding capacity (WHC; g water/g DM), bulk density (g DM/ml), neutral-detergent fibre (NDF) and acid-detergent fibre (ADF) influenced the SFI. The quadratic relationship between SFI and WHC was SFI $=19 \cdot 1($ SEM 3.49) $+10 \cdot 04($ SEM 1.61) WHC-1.11 (SEM 0.17) WHC $(P<0 \cdot 01)$. SFI was also related $(P<0 \cdot 01)$ to NDF and ADF by quadratic functions SFI $=24 \cdot 3(\operatorname{sem} 3 \cdot 55)+0 \cdot 12($ SEM $0 \cdot 229) \mathrm{NDF}-0 \cdot 00012($ SEM $0 \cdot 000036) \mathrm{NDF}^{2}$ and SFI $=30 \cdot 2(\mathrm{SEM} 1 \cdot 95)+0 \cdot 112$ (SEM 0.0232) ADF-0.000343 (SEM 0.0000612) $\mathrm{ADF}^{2}$, respectively. Using broken-stick analyses, the gut capacity was attained when $\mathrm{WHC}=4.53$ (SEM 1.25) g water/g DM, NDF=367 (sEM 29) g/kg DM and ADF=138 (sEM 77) g/kg DM. In conclusion, although threshold values for each were different, WHC, NDF and ADF contents of bulk feeds provide relationships with SFI that can be used to predict gut capacity in weaner pigs.
\end{abstract}

Key words: Dietary fibre: Gut capacity: Scaled feed intake: Weaner pigs: Water-holding capacity

An understanding of feed intake in growing pigs is crucial for the prediction of productivity, sustainability and profitability of pig enterprises ${ }^{(1,2)}$. Prediction of the gut capacities of growing pigs facilitates the nutritionally and economically accurate formulation of feeds. Bulky feeds are expected to reduce the nutrient density of the feed, prompting the pig to consume more feed to meet its nutrient requirements for potential growth $^{(3,4)}$. At some point, voluntary feed intake (VFI) should reach a maximum, become constant or may begin to decrease because of physiological limitation of the gut capacity as the physico-chemical measurements of feed bulk increase.

Knowledge of the gut capacity enables feed compounders to ensure that ingestion of sufficient nutrients by growing pigs is achieved without excessive or restricting nutrients to optimise performance. Together with performance characteristics, measurements of gut capacity can also be used to estimate the economic value of an individual pig at any given stage of growth.

Several reports have suggested that water-holding capacity (WHC) is the most accurate physico-chemical measurement of feed bulk that predicts $\mathrm{VFI}^{(3,4,5)}$. These reports were, however, based on results from studies on a few fibrous sources with a narrow range of WHC. Relationships generated are likely to be inaccurate, given the wide variation in physical properties of fibrous feedstuffs. For example, the WHC for sunflower husks and maize stover are 6.8 and $18.3 \mathrm{~g}$ water/g DM, respectively ${ }^{(6)}$. In addition, the impact of other variables, such as density, acid-detergent fibre (ADF), neutral-detergent fibre (NDF) and crude fibre, on VFI of 'bulky' feeds is poorly understood and warrants further investigation. It is, therefore, crucial to determine the relationship between the physicochemical properties and the VFI in young growing pigs.

The objective of the study was to determine the physicochemical properties of a feed that best describe the relationship between the feed bulk and the scaled feed intake (SFI), such that the gut capacity of a weaner pig can be predicted using these measurements. It was hypothesised that as feed bulk increases, feed intake in weaner pigs will increase linearly to the point where the gut capacity is reached, whereafter no further increase will occur. This point should be related to some physical properties of the feed and to some scaled measure of the size of the pig.

Abbreviations: ADF, acid-detergent fibre; NDF, neutral-detergent fibre; SFI, scaled feed intake; UKZN, University of KwaZulu-Natal; VFI, voluntary feed intake; WHC, water-holding capacity.

*Corresponding author: M. Chimonyo, fax +27 33260 5067, email chimonyo@ukzn.ac.za 


\section{Materials and methods \\ Description of study site}

The study was conducted at the Ukulinga Research Farm, University of KwaZulu-Natal (UKZN), Pietermaritzburg, South Africa, situated in a subtropical hinterland, located at $30^{\circ} 24^{\prime} \mathrm{S}$, $29^{\circ} 24^{\prime} \mathrm{E}$ and is approximately $700 \mathrm{~m}$ above sea level. The climate is characterised by an annual rainfall of $735 \mathrm{~mm}$, which falls mostly in the summer between October and April. Mean annual maximum and minimum temperatures are 25.7 and $8.9^{\circ} \mathrm{C}$, respectively. Light to moderate frost occurs in winter.

\section{Pigs and housing}

The pig house consisted of sixty-two individual pens mounted in a room that had a single heating, lighting and ventilation system. The individual pens were arranged in two rows such that they were thirty-one pens on each side. Each pen measured $1.5 \times 1 \mathrm{~m}^{2}$ and contained a plastic self-feeder trough (Big Dutchman Lean Machine ${ }^{\circledR}$, Postfach) and a lowpressure nipple drinker providing water ad libitum. The weaner pigs were purchased from the New Hanover Lutheran Church farm.

A total of 124 male F1 hybrid pigs (Large White $\times$ Landrace, PIC Group) were moved at 6 weeks of age, weighing $18 \cdot 1$ (SD 1.37) kg body weight, into individual pens in two batches. The pigs were ear tagged for identification purposes. Pigs were not given any antibiotics or growth promoters in their diets, either before or during the trial. The ambient temperature and relative humidity were recorded automatically at every 15 min throughout the trial using a HOBO TEMPERATURE, $\mathrm{RH}^{(}$, 1996 ONSET logger (Onset Computer Corporation). The average temperature and humidity were $21 \cdot 15 \pm 2 \cdot 74^{\circ} \mathrm{C}$ and $42.64 \pm 1.56 \%$, respectively.

\section{Feeds}

A high-quality commercial feed (Express Weaner, Meadow Feeds Limited) with a low level of dietary fibre $(50 \mathrm{~g} / \mathrm{kg}$ DM of total dietary fibre) was used as the basal control feed (Table 1). The basal feed contained $13.7 \mathrm{MJ}$ digestible energy and $180 \mathrm{~g}$ crude protein/kg DM. To have a wide range of physicochemical properties, six fibre sources, namely maize cob, maize stover, sunflower husks grass hay (veld grass), lucerne and sawdust, were selected to dilute the basal diet. The aim was to select fibre sources with a wide range of physico-chemical properties.

Table 1. Major ingredient composition of the basal feed

\begin{tabular}{lc}
\hline Ingredient & $(\mathrm{g} / \mathrm{kg} \mathrm{DM})$ \\
\hline Yellow maize & 426 \\
Soyabean & 176 \\
Soyabean oil cake & 83.8 \\
Whole wheat & 100 \\
Wheat bran & 100 \\
Sunflower oil cake & $75 \cdot 0$ \\
Cape fish & 20.0 \\
Additives & 20.0 \\
\hline
\end{tabular}

From the six fibre sources selected, thirty complete 'bulky' diets were formulated by diluting the basal diet with five inclusion levels for each fibre source. The contents of the fibre sources in the complete diets were 80, 160, 240, 320 and $400 \mathrm{~g} / \mathrm{kg}$. It was assumed that the pigs would increase their intake proportionately to the degree of dilution of the basal feed with the fibre source up to the point where gut capacity is reached. No dietary supplements were added to the diluted feeds.

Analyses of the chemical composition and the bulky characteristics of each of the thirty-one complete diets, shown in Tables 2 and 3, were conducted according to the $\mathrm{AOAC}^{(7)}$. The analyses of diets were performed in the Discipline of Animal and Poultry Science Laboratory at UKZN, Pietermaritzburg.

\section{Experimental design and management of pigs}

Each of the thirty-one diets was fed to four randomly selected pigs over two periods, i.e. two pigs per period, each pig in its own pen. Each treatment was blocked by randomising these on either side of a central passageway. Feed was provided ad libitum. An adaptation period of $10 \mathrm{~d}$ was allowed for each batch, then the pigs were subjected to the treatment diets at 18.1 (SD 1.37) kg body weight for 4 weeks. Pigs were weighed every week throughout the trial and these were regressed to determine mean daily body weight gain. Feed intake was determined by weighing the feed trough at the beginning and end of each week. A plastic tray was placed under each trough to collect feed spillage. The feed spilled was dried, weighed and discarded daily. Weights of feed refusals and spillages were subtracted from the total weight of the feed allocated to determine feed intake for that week.

Weight of the feed consumed each week was divided by 7 to determine the average daily feed intake. To account for differences in mean pig weight between treatments, average daily feed intake was scaled to body weight. A scaled average daily feed intake was calculated as $\mathrm{g}$ feed per kg body weight per $\mathrm{d}$. The research facility was washed, disinfected and rested for 2 weeks after the first batch of pigs had been removed, and a second batch of sixty-two pigs was introduced.

\section{Statistical analyses}

The effects of age of the pigs (week), fibre source, fibre inclusion level, run and their interactions on SFI were determined using the GLM procedure (SAS, 2008; SAS Institute Inc.). The effect of the batch on SFI was not significant and was, therefore, eliminated from the model. The model used was as follows:

$$
Y_{\mathrm{ijklm}}=\mu+a_{\mathrm{i}}+\nu_{\mathrm{j}}+\delta_{\mathrm{k}}+\lambda_{\mathrm{l}}+(\alpha \times \nu \times \delta)_{\mathrm{ijk}}+\varepsilon_{\mathrm{ijklm}},
$$

where $Y_{\mathrm{ijklm}}$ is the SFI; $\mu$ is the overall mean response common to all observations; $\alpha_{\mathrm{i}}$ is the effect of fibre source; $\nu_{\mathrm{j}}$ is the effect of the fibre inclusion level; $\delta_{\mathrm{k}}$ is the effect of the week of feeding; $(\alpha \times \nu)_{\mathrm{ij}}$ is the interaction of fibre source and inclusion level; $(\alpha \times \delta)_{\mathrm{ik}}$ is the interaction of 
Table 2. Chemical composition of the basal diet (B), and diets based on lucerne hay (LC), maize cob (MC), maize stover (MS), sawdust (SD), sunflower husk (SH) and veld grass (VG) at varying inclusion levels

\begin{tabular}{|c|c|c|c|c|c|c|}
\hline $\begin{array}{l}\text { Fibre } \\
\text { source }\end{array}$ & Level $(\mathrm{g} / \mathrm{kg})$ & $\begin{array}{l}\text { DM } \\
(\mathrm{g} / \mathrm{kg})\end{array}$ & $\begin{array}{l}\text { Gross energy } \\
\text { (MJ/kg DM) }\end{array}$ & $\begin{array}{l}\text { Crude protein } \\
\text { (g/kg DM) }\end{array}$ & $\begin{array}{c}\text { Diethyl ether } \\
\text { extract (g/kg DM) }\end{array}$ & $\begin{array}{c}\text { Ash } \\
\text { (g/kg DM) }\end{array}$ \\
\hline B & 0 & 989 & $18 \cdot 1$ & 196 & 52.9 & $61 \cdot 1$ \\
\hline \multirow[t]{5}{*}{ LC } & 80 & 989 & $18 \cdot 1$ & 197 & 49.2 & 63.1 \\
\hline & 160 & 990 & $18 \cdot 1$ & 188 & $45 \cdot 2$ & $65 \cdot 1$ \\
\hline & 240 & 990 & 18.0 & 174 & 41.5 & $67 \cdot 2$ \\
\hline & 320 & 989 & $17 \cdot 9$ & 169 & 39.2 & 69.2 \\
\hline & 400 & 989 & 17.9 & 166 & 33.3 & 71.3 \\
\hline \multirow[t]{5}{*}{$\mathrm{MC}$} & 80 & 989 & 18.0 & 186 & $51 \cdot 2$ & 59.0 \\
\hline & 160 & 990 & 17.9 & 168 & $45 \cdot 9$ & 54.9 \\
\hline & 240 & 990 & 17.9 & 153 & $45 \cdot 2$ & 53.2 \\
\hline & 320 & 990 & 17.9 & 139 & 41.3 & $52 \cdot 1$ \\
\hline & 400 & 991 & $17 \cdot 8$ & 116 & 39.9 & $46 \cdot 7$ \\
\hline \multirow[t]{5}{*}{ MS } & 80 & 990 & 18.0 & 179 & $50 \cdot 1$ & 62.3 \\
\hline & 160 & 990 & 17.9 & 170 & 44.9 & $64 \cdot 2$ \\
\hline & 240 & 989 & $17 \cdot 8$ & 148 & 39.3 & 65.3 \\
\hline & 320 & 989 & $17 \cdot 7$ & 143 & $37 \cdot 1$ & 66.4 \\
\hline & 400 & 989 & 17.6 & 141 & 31.9 & 66.5 \\
\hline \multirow[t]{5}{*}{ SD } & 80 & 989 & 17.4 & 117 & 51.5 & 53.7 \\
\hline & 160 & 989 & $17 \cdot 2$ & 165 & $47 \cdot 7$ & $48 \cdot 3$ \\
\hline & 240 & 989 & $17 \cdot 1$ & 146 & $45 \cdot 6$ & $44 \cdot 1$ \\
\hline & 320 & 989 & $17 \cdot 1$ & 131 & $42 \cdot 4$ & 41.6 \\
\hline & 400 & 989 & $17 \cdot 0$ & 118 & $36 \cdot 7$ & 39.2 \\
\hline \multirow[t]{5}{*}{$\mathrm{SH}$} & 80 & 989 & $18 \cdot 2$ & 167 & $54 \cdot 1$ & $56 \cdot 6$ \\
\hline & 160 & 989 & 18.3 & 146 & 55.4 & 53.8 \\
\hline & 240 & 989 & 18.5 & 135 & $55 \cdot 7$ & 51.6 \\
\hline & 320 & 989 & 18.7 & 132 & 56.6 & 48.5 \\
\hline & 400 & 989 & 19.2 & 124 & $57 \cdot 3$ & 44.9 \\
\hline \multirow[t]{5}{*}{ VG } & 80 & 989 & 18.0 & 186 & 51.7 & 60.4 \\
\hline & 160 & 990 & 18.2 & 145 & $49 \cdot 3$ & 61.9 \\
\hline & 240 & 990 & 17.9 & 136 & $40 \cdot 7$ & 63.9 \\
\hline & 320 & 990 & 17.9 & 121 & 36.6 & 64.9 \\
\hline & 400 & 990 & $17 \cdot 8$ & 113 & 32.4 & 65.9 \\
\hline SEM & & 0.94 & 0.020 & 1.22 & 0.34 & 0.70 \\
\hline
\end{tabular}

fibre source and week of feeding; $(\nu \times \delta)_{\mathrm{jk}}$ is the interaction of fibre inclusion level and week of feeding; $(\alpha \times \nu \times \delta)_{\mathrm{ijk}}$ is the interaction of fibre source, fibre inclusion level and week of feeding; and $\varepsilon_{\mathrm{ijklm}}$ is the residual error.

Relationships between week of feeding and SFI for each fibre inclusion level were determined using PROC RSREG (SAS Institute Inc.) $^{(8)}$. Stepwise regression in SAS (2008; SAS Institute Inc.) was used to identify the physico-chemical properties that influenced the SFI. The quadratic response surface model (PROC RSREG) procedure of SAS (2008; SAS Institute Inc.) was used to determine the relationship between the SFI and each of the physico-chemical properties selected using stepwise regression. To estimate the threshold at which the physico-chemical property of a feed causes the SFI to be constant or decrease with feed bulk, the simplest piecewise regression (broken-stick) analysis was conducted using the NLIN procedure (SAS, 2008; SAS Institute Inc.). In this model, breakpoints were used to estimate the thresholds of the physico-chemical properties of the feed at which the amount of feed consumed will be constrained by the gut capacity of the pig. The model was developed as follows:

$$
\begin{aligned}
& \mathrm{SFI}_{\mathrm{i}}=\gamma_{0}+\gamma_{1}\left(x_{\mathrm{i}}\right)+\gamma_{2}\left(x_{\mathrm{i}}>x_{\mathrm{c}}\right)\left(x_{\mathrm{i}}-x_{\mathrm{c}}\right)+\varepsilon_{\mathrm{i}}, \\
& \quad \text { when }\left(x_{\mathrm{i}}>x_{\mathrm{c}}\right)=1 .
\end{aligned}
$$

Using parameters $\left(\gamma_{0}, \gamma_{1}\right.$ and $\left.\gamma_{2}\right)$ and $x_{\mathrm{c}}$, the two segmented simple regression functions were as follows:

$$
\begin{gathered}
\mathrm{SFI}_{\mathrm{j}}=\gamma_{0}+\gamma_{1}\left(x_{\mathrm{i}}\right), \quad \text { for } x_{\mathrm{i}} \leq x_{\mathrm{c}} \text { and } \\
\mathrm{SFI}_{\mathrm{k}}=\mathrm{SFI}_{0}+\left(\gamma_{1}+\gamma_{2}\right) x_{\mathrm{i}}, \quad \text { for } x_{\mathrm{i}} \geq x_{\mathrm{c}}
\end{gathered}
$$

where $\mathrm{SFI}_{\mathrm{i}}$ is the $\mathrm{SFI}$ when VFI is maximum; $\mathrm{SFI}_{0}$ is the SFI when $x_{\mathrm{i}}=0 ; \gamma_{0}$ is the intercept or minimum SFI when $x_{\mathrm{c}}<0 ; \gamma_{1}$ is the rate of change of SFI when $x_{\mathrm{i}}<x_{\mathrm{c}} ; \gamma_{2}$ is the rate of increase in SFI when $x_{\mathrm{i}}>x_{\mathrm{c}} ; x_{\mathrm{i}}$ is the value of the physico-chemical property of the feed; and $x_{\mathrm{c}}$ is the optimum physico-chemical property value when the gut capacity is attained.

\section{Ethical considerations}

The care and use of the pigs were performed according to the ethical needs by the Certification of Authorization to Experiment on Living Animals provided by the UKZN Animal Ethics Committee (reference no. 096/11/Animal).

\section{Results}

\section{Effects of fibre source, inclusion level and week on} scaled feed intake

Table 4 shows the untransformed least square means for each inclusion level. The SFI varied with fibre source $(P<0.05)$ and inclusion levels. The changes in SFI of the pigs given incremental levels of each of the bulky feeds 
Table 3. Bulk characteristics $(\mathrm{g} / \mathrm{kg} \mathrm{DM})$ of the basal diet (B) and diets based on lucerne hay (LC), maize cob (MC), maize stover (MS), sawdust (SD), sunflower husk (SH) and veld grass (VG) at varying inclusion levels

\begin{tabular}{|c|c|c|c|c|c|}
\hline $\begin{array}{l}\text { Fibre } \\
\text { source }\end{array}$ & $\begin{array}{l}\text { Level } \\
(\mathrm{g} / \mathrm{kg})\end{array}$ & $\begin{array}{c}\text { NDF } \\
(\mathrm{g} / \mathrm{kg} \mathrm{DM})\end{array}$ & $\begin{array}{c}\text { ADF } \\
(\mathrm{g} / \mathrm{kg} \mathrm{DM})\end{array}$ & $\begin{array}{l}\text { Density } \\
(\mathrm{g} \mathrm{DM} / \mathrm{ml})\end{array}$ & $\begin{array}{c}\text { WHC } \\
\text { (g water/g DM) }\end{array}$ \\
\hline$B$ & 0 & $192 \cdot 3$ & 88.4 & 1.45 & 3.76 \\
\hline \multirow[t]{5}{*}{ LC } & 80 & 218 & 101 & 1.54 & 3.65 \\
\hline & 160 & 261 & 126 & 1.46 & $4 \cdot 26$ \\
\hline & 240 & 302 & 151 & 1.39 & 5.04 \\
\hline & 320 & 344 & 176 & $1 \cdot 32$ & $5 \cdot 56$ \\
\hline & 400 & 386 & 200 & $1 \cdot 27$ & $6 \cdot 52$ \\
\hline \multirow[t]{5}{*}{ MC } & 80 & 231 & 112 & 1.52 & $3 \cdot 17$ \\
\hline & 160 & 294 & 147 & 1.47 & 3.57 \\
\hline & 240 & 355 & 181 & 1.42 & 4.08 \\
\hline & 320 & 401 & 218 & $1 \cdot 25$ & 4.41 \\
\hline & 400 & 457 & 251 & $1 \cdot 22$ & $4 \cdot 75$ \\
\hline \multirow[t]{5}{*}{ MS } & 80 & 192 & 111 & 1.49 & $4 \cdot 15$ \\
\hline & 160 & 228 & 143 & $1 \cdot 31$ & $5 \cdot 24$ \\
\hline & 240 & 280 & 175 & $1 \cdot 30$ & 6.48 \\
\hline & 320 & 332 & 208 & $1 \cdot 12$ & 7.49 \\
\hline & 400 & 383 & 240 & $1 \cdot 10$ & $8 \cdot 31$ \\
\hline \multirow[t]{5}{*}{ SD } & 80 & 257 & 128 & 1.54 & 3.41 \\
\hline & 160 & 318 & 178 & 1.49 & 3.95 \\
\hline & 240 & 379 & 227 & 1.43 & $4 \cdot 27$ \\
\hline & 320 & 440 & 277 & 1.40 & $4 \cdot 79$ \\
\hline & 400 & 501 & 327 & $1 \cdot 31$ & $5 \cdot 21$ \\
\hline \multirow[t]{5}{*}{$\mathrm{SH}$} & 80 & 223 & 94.5 & 1.49 & $3 \cdot 16$ \\
\hline & 160 & 270 & 111 & 1.44 & 3.48 \\
\hline & 240 & 317 & 126 & $1 \cdot 33$ & $3 \cdot 76$ \\
\hline & 320 & 363 & 142 & $1 \cdot 31$ & 4.06 \\
\hline & 400 & 410 & 158 & $1 \cdot 21$ & $4 \cdot 38$ \\
\hline \multirow[t]{5}{*}{ VG } & 80 & 230 & 122 & 1.51 & $3 \cdot 76$ \\
\hline & 160 & 284 & 167 & 1.50 & $4 \cdot 28$ \\
\hline & 240 & 338 & 214 & 1.47 & $5 \cdot 14$ \\
\hline & 320 & 391 & 259 & $1 \cdot 31$ & 6.45 \\
\hline & 400 & 444 & 304 & $1 \cdot 20$ & $7 \cdot 13$ \\
\hline SEM & & $2 \cdot 11$ & 0.89 & 0.03 & 0.09 \\
\hline
\end{tabular}

NDF, neutral-detergent fibre; ADF, acid-detergent fibre; WHC, water-holding capacity.

during the 4-week period are illustrated in Table 5 . There was a significant three-way (fibre source $\times$ inclusion level $\times$ week) interaction on the SFI. At $80 \mathrm{~g} / \mathrm{kg}$ inclusion level, the SFI was similar across all fibre sources during the feeding period but it increased for sawdust-based diets. The SFI decreased $(P<0.001)$ during the successive week of feeding when the pigs were given the basal diet and had the lowest $(P<0.001)$ intake values of almost all 'bulky' diets, except for a diet with $400 \mathrm{~g} / \mathrm{kg}$ grass hay. As the level of fibre inclusion increased, the SFI increased $(P<0.05)$ during each week, but at 80 and $160 \mathrm{~g} / \mathrm{kg}$ inclusion levels, intake started decreasing $(P<0.01)$ such that during weeks 3 and 4 , the SFI was close to constant across all the feeds. There was, however, a continuous increase $(P<0 \cdot 001)$ in SFI for sawdust, veld grass and $240 \mathrm{~g} / \mathrm{kg}$ maize cob-based diet as well as for 320 and $400 \mathrm{~g} / \mathrm{kg}$ maize stover inclusion levels.

\section{Prediction of feed intake and estimation of gut capacity}

Fig. 1 illustrates the relationships between SFI of weaner pigs and WHC, NDF, bulk density and ADF of fibrous feeds. There was a significant quadratic decrease $(P<0.001)$ in SFI as the
WHC, ADF and NDF of the diets increased. An increase in the bulk density of the feed was associated with a linear decrease in SFI $(P<0 \cdot 001)$.

The broken-stick model was used to determine the thresholds of the physico-chemical properties of the bulky feeds, indicating the break point when the maximum SFI was attained. A broken-stick model of regression could not be fitted to the dataset for SFI and bulk density. Using WHC, $\mathrm{ADF}$ and NDF as the descriptors, the maximum SFI was reached at 4.5 (SEM 1.25) g water/g DM, 367 (SEM 29) g/kg $\mathrm{DM}$ and 138 (SEM 77) g/kg DM, respectively (Table 6). This occurred when VFI became constant or started to decrease due to limitations of the gut capacity of the pig.

\section{Discussion}

Pigs eat at a level to allow the potential performance or maximum biological efficiency to be achieved, unless constrained in some way ${ }^{(5)}$. Gut capacity is reached when the pig, given a constraining feed, reaches an equilibrium level of feed intake that is below the desired level required for the genetic potential to be achieved ${ }^{(9)}$. Predictive relationships between feed bulk and VFI had been developed using a limited number of diets ${ }^{(1,3,4)}$. Due to a narrow range of physicochemical measurements of bulkiness and a limited number of fibrous diets used in these previous experiments, the relationship established may not be comprehensive in providing accurate predictions of feed intake.

The fibre content in the diet is defined solely as the $\mathrm{NSP}^{(2)}$. A wide variety of fibrous ingredients were used in the present study, because all the NSP do not behave in a similar way in the gastrointestinal tract. For example, insoluble NSP, such as cellulose and xylans, can hold water (as they behave like sponges in the gastrointestinal tract), resulting in considerable bulking properties. Soluble NSP, on the other hand, form gels and contribute to the viscosity of the contents of the gastrointestinal tract ${ }^{(4)}$.

The increase in intake of bulky feeds, as the inclusion level of the fibre increased during the beginning of the trial, suggests that pigs increased consumption to compensate for the increase in indigestible material content so that they could acquire sufficient nutrients to achieve their growth potential $^{(5)}$. The decrease in the SFI of the pigs given the

Table 4. Least square means for average daily feed intake for diets containing lucerne hay (LC), maize cob (MC), maize stover (MS), sawdust (SD), sunflower husk (SH) and veld grass (VG) at varying inclusion levels*

\begin{tabular}{lccccc}
\hline & \multicolumn{5}{c}{ Inclusion level $(\mathrm{g} / \mathrm{kg})$} \\
\cline { 2 - 6 } $\begin{array}{l}\text { Source } \\
\text { of fibre }\end{array}$ & 80 & 160 & 240 & 320 & 400 \\
\hline MC & 1.39 & 1.52 & 1.31 & 1.23 & 1.13 \\
SD & 1.48 & 1.42 & 1.24 & 1.26 & 1.01 \\
VG & 1.17 & 1.01 & 0.87 & 0.76 & 0.64 \\
SH & 1.40 & 1.41 & 1.26 & 1.29 & 1.32 \\
LC & 1.33 & 1.18 & 1.29 & 1.13 & 0.89 \\
MS & 1.28 & 1.18 & 1.08 & 0.81 & 0.71 \\
\hline
\end{tabular}

${ }^{*}$ Least square mean for pigs on the control diet was 1.36 (SEM 0.069) g/kg. The standard error for the intakes was $0.097 \mathrm{~g} / \mathrm{kg}$. 
Table 5. Weekly scaled feed intake ( $\mathrm{g} / \mathrm{kg}$ per d) of pigs given incremental levels of bulky feed containing lucerne hay (LC), maize cob $(\mathrm{MC})$, maize stover (MS), sawdust (SD), sunflower (SH) and veld grass (VG)*

(Regression coefficients and standard errors)

\begin{tabular}{|c|c|c|c|c|c|c|c|c|c|}
\hline \multirow[b]{2}{*}{$\begin{array}{l}\text { Fibre } \\
\text { source }\end{array}$} & \multirow[b]{2}{*}{$\begin{array}{c}\text { Level } \\
\text { (g/kg DM) }\end{array}$} & \multicolumn{4}{|c|}{ Week } & \multicolumn{2}{|c|}{ Linear† } & \multicolumn{2}{|c|}{ Quadratic } \\
\hline & & 1 & 2 & 3 & 4 & $\begin{array}{c}\text { Regression } \\
\text { coefficient }\end{array}$ & SEM & $\begin{array}{c}\text { Regression } \\
\text { coefficient }\end{array}$ & SEM \\
\hline Basal & 0 & $42 \cdot 8$ & 38.6 & 36.9 & 35.7 & & & & \\
\hline \multirow[t]{5}{*}{ LC } & 80 & 38.6 & 43.8 & $45 \cdot 8$ & $45 \cdot 6$ & & & & \\
\hline & 160 & $36 \cdot 6$ & 38.6 & 38.0 & 43.1 & & & & \\
\hline & 240 & 38.2 & $42 \cdot 3$ & $44 \cdot 4$ & 47.3 & $2 \cdot 76$ & 0.967 & & \\
\hline & 320 & $38 \cdot 6$ & 40.6 & $46 \cdot 4$ & 48.0 & & & & \\
\hline & 400 & 34.6 & 35.6 & 40.5 & 41.9 & $5 \cdot 72$ & 1.381 & & \\
\hline \multirow[t]{5}{*}{ MC } & 80 & 37.5 & 39.5 & $41 \cdot 2$ & $42 \cdot 1$ & & & & \\
\hline & 160 & $36 \cdot 6$ & 39.6 & $41 \cdot 7$ & $42 \cdot 6$ & & & & \\
\hline & 240 & $40 \cdot 3$ & $40 \cdot 1$ & 42.5 & 44.7 & & & & \\
\hline & 320 & 36.5 & 41.6 & $45 \cdot 4$ & $47 \cdot 1$ & 3.80 & 0.997 & & \\
\hline & 400 & 37.0 & 39.2 & 41.6 & 46.8 & 3.40 & 1.163 & & \\
\hline \multirow[t]{5}{*}{ MS } & 80 & 35.9 & 36.1 & $35 \cdot 6$ & 37.8 & & & & \\
\hline & 160 & 34.4 & 37.4 & $42 \cdot 6$ & 43.5 & & & & \\
\hline & 240 & $35 \cdot 6$ & 38.6 & 41.7 & 45.9 & & & & \\
\hline & 320 & $35 \cdot 8$ & 37.0 & 37.9 & 41.9 & & & & \\
\hline & 400 & $26 \cdot 8$ & 31.6 & 35.4 & 35.1 & & & & \\
\hline \multirow[t]{5}{*}{ SD } & 80 & $35 \cdot 6$ & 38.6 & 42.5 & 46.5 & 3.56 & 1.343 & & \\
\hline & 160 & $38 \cdot 1$ & 40.5 & 43.2 & 47.9 & & & & \\
\hline & 240 & $39 \cdot 2$ & $42 \cdot 1$ & 43.6 & $45 \cdot 8$ & $2 \cdot 33$ & 0.701 & & \\
\hline & 320 & 38.4 & $40 \cdot 2$ & $45 \cdot 9$ & 51.3 & & & & \\
\hline & 400 & $35 \cdot 2$ & 41.6 & $37 \cdot 2$ & 42.5 & $6 \cdot 15$ & $2 \cdot 209$ & & \\
\hline \multirow[t]{5}{*}{$\mathrm{SH}$} & 80 & 39.1 & 39.2 & $41 \cdot 1$ & 40.4 & & & & \\
\hline & 160 & $45 \cdot 1$ & 43.3 & $41 \cdot 8$ & 41.2 & & & & \\
\hline & 240 & $43 \cdot 7$ & 43.6 & 43.9 & 44.0 & & & & \\
\hline & 320 & 43.5 & 44.1 & $44 \cdot 2$ & 45.0 & & & & \\
\hline & 400 & $33 \cdot 3$ & 45.1 & $51 \cdot 1$ & 49.6 & 28.9 & 9.69 & -4.58 & 1.91 \\
\hline \multirow[t]{5}{*}{ VG } & 80 & $35 \cdot 6$ & 43.4 & $43 \cdot 8$ & 44.4 & & & & \\
\hline & 160 & $36 \cdot 2$ & 44.9 & $45 \cdot 6$ & 45.5 & $2 \cdot 32$ & 0.835 & & \\
\hline & 240 & $32 \cdot 2$ & 43.7 & $47 \cdot 1$ & 49.4 & 4.25 & 0.984 & & \\
\hline & 320 & 28.9 & 31.0 & $37 \cdot 8$ & $42 \cdot 2$ & 6.49 & 1.411 & & \\
\hline & 400 & $27 \cdot 4$ & 33.3 & 33.6 & 35.1 & & & & \\
\hline
\end{tabular}

* There was a significant (fibre source $\times$ inclusion level $\times$ week) interaction on scaled feed intake.

† Regression coefficient significant at $P<0.05$.

control diet was due to the low WHC of the feed and adaptation to the diet, which allowed pigs to consume adequate nutrients to meet their requirements for maintenance and growth. As expected, inclusion of fibre limited the nutrient supply that was required for maintenance and growth. When 80 or $160 \mathrm{~g} / \mathrm{kg}$ of all fibre sources, except grass hay and sawdust, were included in the diets, feed intake increased and then became constant towards the end of the trial, suggesting that the pigs gradually increased their ability to cope with the bulky feeds. Continuous increase in intake of sawdust-based diets could be attributed to their low abilities to bind water within their matrices ${ }^{(3,4)}$. As sawdust is indigestible, its inclusion decreased the nutrient density, thereby stimulating consumption of more feed to meet the desired nutrient requirements of the pigs.

The SFI at 80,160 and $240 \mathrm{~g} / \mathrm{kg}$ maize cob inclusion levels were similar during the feeding period. Similar findings have been obtained in earlier reports, where no differences in average daily feed intake were observed in growing pigs given diets that contained maize cob at 100 and $300 \mathrm{~g} / \mathrm{kg}$ inclusion levels ${ }^{(10)}$. The similarities in intakes across these levels are largely due to the uniformity of the WHC and the bulk densities of the feeds. Maize cob meal has low WHC. The uniformity in WHC of the maize cob-based diets could be due to its low WHC, implying that it has little additive effect on the overall bulk content of the feed, even when included at high inclusion levels in the diet. Furthermore, maize cob is highly soluble, suggesting that it is readily available for microbial fermentation and may increase the transit time in the gastrointestinal tract, thereby limiting feed consumption. It is, therefore, imperative to estimate changes in the WHC of the maize cob-based digesta along the gut.

$\mathrm{NDF}, \mathrm{ADF}$ and bulk density were significant in predicting average daily feed intake, contradicting earlier reports ${ }^{(3,4)}$. The increase in NDF content in the diet causes gut distension, leading to a reduction in the availability of other non-fibrous feed ingredients for digestion. Feed intake is consequently reduced. The $R^{2}$ values were, however, low (between 10 and $19 \%$ ), indicating that the physico-chemical measures of bulkiness do not provide comprehensive descriptions of feed intake, unless when the intake is scaled per unit body weight.

The observed quadratic relationship between SFI and WHC indicates the existence of an equilibrium intake level, where maximum SFI is reached and intake starts to decrease. That point defines the gut capacity of the pig. WHC measures the ability of the feed to hold water; thus, a diet with a high 

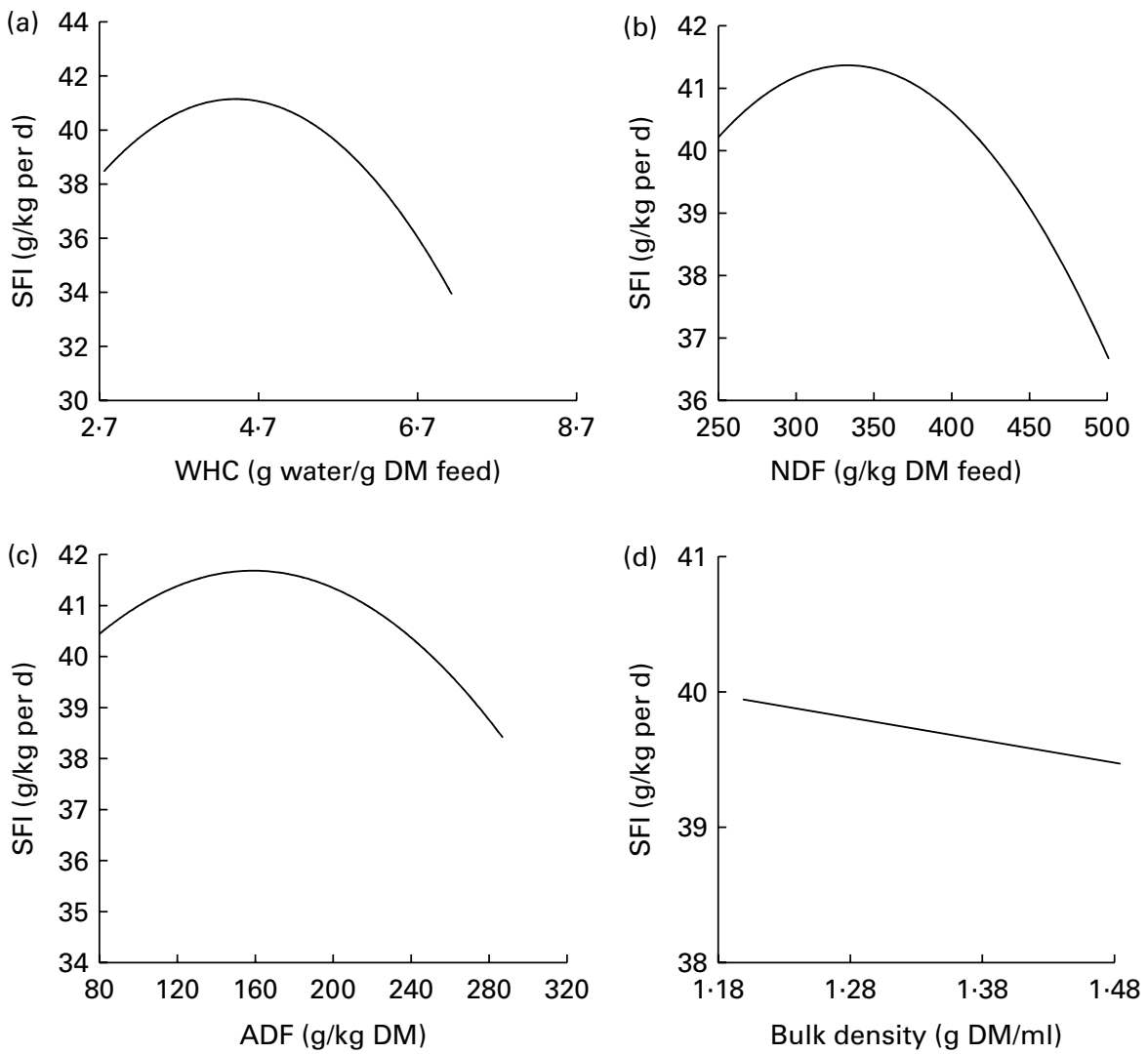

Fig. 1. Prediction of the scaled feed intake (SFI) using (a) water-holding capacity (WHC, $Y=-1.11 x^{2}+10.04 x+19\left(R^{2} 0.72 ; P<0.001\right)$ ), (b) neutral-detergent fibre (NDF, $Y=-0.00012 x^{2}+0.11 x+24\left(R^{2} 0.60 ; P<0.001\right)$ ), (c) acid-detergent fibre (ADF, $\left.Y=-0.00029 x^{2}+0.13 x+30\left(R^{2} 0.65 ; P<0.001\right)\right)$ and (d) bulk density $\left(Y=-4.16 x+45.7\left(R^{2} 0.53 ; P<0.001\right)\right)$ of fibrous feeds.

WHC can hold more water and occupies more room in the gut. Using the broken-stick model, the maximum value of WHC of the feed at which the gut capacity constrained intake was found to be $4.53 \mathrm{~g}$ water/g DM. Furthermore, increase in WHC of the feeds beyond this level caused a decrease in SFI, because the capacity of the gut for feed was filled up with the water molecules being held within the fibre matrix, thus initiating swelling. The quadratic relationship between SFI and WHC in the present study could be plotted owing to the wide variety of fibre sources (and wide range of the WHC) used. Dietary fibres have complex chemical properties, physical composition with variable metabolic effects. The optimum inclusion level for each fibre source should, therefore, depend on the WHC of the feeding material used.

Using only three sources of bulk, it was reported that the quantity of feed was constant at $174 \mathrm{~g} / \mathrm{kg}$ per $\mathrm{d}^{(3)}$. That quantity (the product of maximum SFI and WHC) defines the maximum limit for weaner pigs. By extrapolation, the observed limit at the WHC of $4.53 \mathrm{~g}$ water/g DM translates to an SFI of $41.65 \mathrm{~g} / \mathrm{kg}$ body weight. This suggests that gut capacity in the piglets used in the present study is attained at $189 \mathrm{~g} / \mathrm{kg}$ per $\mathrm{d}$.

Apart from WHC, NDF and ADF content and bulk density were significant in the prediction of SFI. The NDF, ADF and density could be used to predict the gut capacity of pigs.

Table 6. Threshold values of the physico-chemical properties when gut capacity is attained ${ }^{*}$

(Mean values with their standard errors)

\begin{tabular}{|c|c|c|c|c|c|c|c|c|c|}
\hline \multirow{2}{*}{$\begin{array}{l}\text { Physico-chemical } \\
\text { property }\end{array}$} & \multicolumn{2}{|c|}{$\gamma_{0}$} & \multicolumn{2}{|c|}{$\gamma_{1}$} & \multicolumn{2}{|c|}{$\gamma_{2}$} & \multicolumn{2}{|c|}{$x_{\mathrm{c}}$} & \multirow[b]{2}{*}{$P \dagger$} \\
\hline & Mean & SEM & Mean & SEM & Mean & SEM & Mean & SEM & \\
\hline WHC (g water/g DM) & $31 \cdot 3$ & $1 \cdot 12$ & 2.57 & 0.234 & $-5 \cdot 60$ & 0.791 & 4.53 & $1 \cdot 25$ & $<0.001$ \\
\hline NDF (g/kg DM) & $35 \cdot 6$ & $3 \cdot 12$ & 0.021 & 0.012 & -0.047 & 0.012 & 367 & $29 \cdot 3$ & $<0.001$ \\
\hline ADF (g/kg DM) & $38 \cdot 2$ & $5 \cdot 12$ & 0.013 & 0.0025 & -0.112 & 0.085 & 138 & $77 \cdot 4$ & $<0.01$ \\
\hline
\end{tabular}

WHC, water-holding capacity; NDF, neutral-detergent fibre; ADF, acid-detergent fibre.

${ }^{*}$ For the description of variables, see text.

† Significance levels for the $x_{c}$ value. 
The broken-stick model indicated that maximum NDF content of the feed that constrained the SFI when the gut capacity was attained at a break point of 367 (SEM 29) g/kg DM corresponded to less than $320 \mathrm{~g} / \mathrm{kg}$ inclusion level of all the fibre sources used. In addition, when the ADF content of the feed increased, it followed the same trend as that observed with the NDF, constraining the gut capacity at $138 \mathrm{~g} / \mathrm{kg} \mathrm{DM}$; however, the maximum ADF value corresponded to $160 \mathrm{~g} / \mathrm{kg}$ inclusion level of all the fibre sources, except sunflower husks, which has a corresponding inclusion level of $320 \mathrm{~g} / \mathrm{kg}$ veld grass at this break point. The break points of ADF and NDF values suggest that, if decisions of including fibrous ingredients in weaner diets are being considered when these are available at reasonable costs, the ADF and the NDF content in the diets should not exceed the aforementioned inclusion levels to facilitate sufficient intake of nutrients required for growth. In an earlier report ${ }^{(3)}$, crude fibre and NDF could not account for the effects on the feed intake. The use of a wide range of diets in the present study was, therefore, necessary to generate accurate relationships.

The rate of change of SFI after the breakpoint is reached shows that, for all the physico-chemical properties used to estimate gut capacity, continued increase in bulkiness decreased feed intake. The reduction in feed intake indicates that the gastrointestinal tract is not adapted to fibrous feeds ${ }^{(11)}$. The negative linear relationship between bulk density and VFI can also be ascribed to the effect of increasing fibre that is less dense and occupying more space than the conventional diet. The degree of consistency of the feed components reduced the quantity of less bulky material per unit volume required to meet the pigs' desired nutrient requirement. Consequently, more space per unit mass was required to accommodate the feed in the gut, thereby limiting the SFI. An increase in bulk density did not result in a break point, so this measure of feed bulk is not an accurate indicator of the bulk capacity of a piglet.

\section{Conclusions}

As the bulkiness of the feed increased, the SFI was constrained by the gut capacity. Although WHC, NDF and ADF all provide relationships with SFI that can be used to predict gut capacity of weaner pigs, the threshold values were different. In most cases, where the bulk content of the feed increased beyond the threshold value marking the break point, the amount of feed consumed decreased. For the weaner pigs used in the present study, it can be concluded that body weight is an appropriate scaling factor. However, it would be appropriate to determine whether body weight could still be appropriate as a scaling factor when estimating gut capacity in older, larger pigs.

\section{Acknowledgements}

We acknowledge the financial support from the UKZN Competitive Research Grant. We thank the staff at the Ukulinga Research Farm and at the Animal and Poultry Science Laboratory for taking care of the pigs and analysing feed samples, respectively. The contribution of the authors was as follows: S. P. N. designed the research project and wrote the manuscript (as part of his MSc programme) on the basis of a rough draft prepared by R. M. G. and M. C. Critical revisions of the manuscript were performed by R. M. G. and M. C. The authors declare no conflict of interest related to the present study.

\section{References}

1. Whittemore EC, Emmans GC \& Kyriazakis I (2003) The relationship between live weight and the intake of 'bulky' foods in pigs. Anim Sci 76, 89-100.

2. Bindelle J, Leterme P \& Buldgen A (2008) Nutritional and environmental consequences of dietary fibre in pig nutrition: a review. Biotechnol Agron Soc Environ 12, 69-80.

3. Kyriazakis I \& Emmans GC (1995) The voluntary feed intake of pigs given feeds based on wheat bran, dried citrus pulp and grass meal, in relations to measurements of bulk. $\mathrm{Br} \mathrm{J}$ Nutr 73, 191-207.

4. Tsaras LN, Kyriazakis I \& Emmans GC (1998) The prediction of the voluntary food intake of pigs on poor quality foods. Anim Sci 66, 713-723.

5. Whittemore EC, Kyriazakis I, Emmans GC, et al. (2001) Tests of two theories of food intake using growing pigs. 1. The effect of ambient temperature on the intake of foods of differing bulk content. Anim Sci 72, 351-360.

6. Ndou SP (2012) Prediction of gut capacity of growing pigs using physicochemical properties. MSc Thesis, University of KwaZulu-Natal, Pietermatitburg.

7. AOAC (1990) Official Methods of Analysis, 16th ed. Washington DC: Association of Analytical Chemists.

8. SAS (2008) SAS User's Guide: Statistics, Version 9.1. Cary, NC: SAS Institute.

9. Kyriazakis I \& Emmans GC (1999) The voluntary food intake and diet selection of pigs. In A Quantitative Biology of the Pig, pp. 229-248 [I Kyriazakis, editor]. Wallingford: CAB International.

10. Kanengoni AT, Dzama K, Chimonyo M, et al. (2004) Growth performance and carcass traits of Large White, Mukota and their F1 crosses fed on graded levels of maize cobs. Anim Sci 78, 61-66.

11. Whittemore EC, Emmans GC \& Kyriazakis I (2003) The problem of predicting food intake during the period of adaptation to a new food: a model. Br J Nutr 89, 383-398. 